\title{
Influence of Maturation on Sports Injuries Profile in Portuguese Youth ${ }^{\dagger}$
}

\author{
Lara Costa e Silva *(D), Júlia Teles $(\mathbb{D}$ and Isabel Fragoso
}

check for

updates

Citation: Silva, L.C.e.; Teles, J.; Fragoso, I. Influence of Maturation on Sports Injuries Profile in Portuguese Youth. Med. Sci. Forum 2021, 5, 43. https://doi.org/10.3390/msf 2021005043

Academic Editors: Helena Barroso and Cidália Castro

Published: 22 July 2021

Publisher's Note: MDPI stays neutral with regard to jurisdictional claims in published maps and institutional affiliations.

Copyright: (c) 2021 by the authors. Licensee MDPI, Basel, Switzerland. This article is an open access article distributed under the terms and conditions of the Creative Commons Attribution (CC BY) license (https:// creativecommons.org/licenses/by/ $4.0 /)$.
CIPER, Faculty of Human Kinetics, University of Lisbon, 1495-751 Cruz Quebrada, Portugal; jteles@fmh.ulisboa.pt (J.T.); ifragoso@fmh.ulisboa.pt (I.F.)

* Correspondence: laras@uatlantica.pt

+ Presented at the 5th International Congress of CiiEM-Reducing Inequalities in Health and Society, Online, 16-18 June 2021.

\begin{abstract}
Physical activity (PA) is beneficial, enhancing healthy development. However, it is estimated that one third of school-age children practicing sport regularly suffer from a serious injury. Maturation can make young athletes more vulnerable to sports injuries and increased knowledge about injury with specific PA exposure data is important to an overall risk management strategy. The aim of this study was to determine the influence of maturation on sports injury profiles in Portuguese youths. Distance to peak height velocity (PHV) was a significant predictor of injury patterns in children and adolescents of both sexes.
\end{abstract}

Keywords: injuries; children and adolescents; bone age; peak height velocity; physical activity level

\section{Introduction}

Musculoskeletal injuries are the most common injuries in youth sports. Growth spurts, maturity-associated variations, and a lack of complex motor skills needed for certain sports are among the risk factors that may play an important role in the growing athlete [1-3]. An epidemic of both acute and overuse injuries has been considered as children make the transition to adolescence. Enhanced environments for injury can occur and several authors have reported structural and tissue changes that may contribute to this situation [1-3]. As children and adolescents participate in sports in record numbers, targeting risk groups is important [3]. Therefore, our aim was to determine the influence of maturation on sports injury profiles of Portuguese youths.

\section{Materials and Methods}

The injury profiles and PA level information were obtained by LESADO and RAPIL II questionnaires. They were distributed to 651 participants aged between 10 and 18 years attending four schools. Maturity measures were evaluated through maturity offset (time before or after peak height velocity-PHV) and the Tanner-Whitehouse III method. Univariate analysis was used to identify the set of candidate predictors for the regression analysis that was used to determine significant predictors of injury occurrence, injury rate, injury type, and body area injury location. The Ethics Committee of the Faculty of Human Kinetics approved the research protocol. Before inclusion in the study all subjects' parents gave their written informed consent. STROBE guidelines were followed.

\section{Results and Discussion}

A total of 651 subjects participated in this study, aged between 10 and 18 years (Mean $=13.7$ years; Standard Deviation $=1.8$ years $)$. A total of 247 subjects reported a sports injury during the previous six months (37.9\%; 95\% CI: 34.2-41.7\%). Considering the analysis by sex, $42.1 \%$ of the boys and $33.9 \%$ of the girls reported an injury. The injury rate was 11.8 per $1000 \mathrm{~h}$. Regarding predictors, the probability of injury increased 
approximately two times in girls who had already passed PHV ( $p=0.009)$. Early mature girls $(p=0.007)$, with higher bone age $(p=0.012)$ and close to PHV $(p=0.033)$, showed a higher injury rate. Additionally, as maturity offset decreased, the chances of girls having a strain or a fracture increased 2 times $\left(\chi^{2}(2)=15.115, p=0.001\right)$. In boys, the probability of injury to the upper limbs was higher before PHV and in the lower limbs it was higher after $\operatorname{PHV}\left(\chi^{2}(2)=6.014, p=0.049\right)$.

Some injury risk factors are unique to the growing athlete. Sports injury profiles in youths are significantly influenced by maturation [2]. Girls near PHV may be particularly vulnerable to sports injury risk due to the physiological processes of growth. An increase in traumatic injuries takes place mainly during the year of $\mathrm{PHV}$, while the increase in overuse injuries persists in the year after PHV. Imbalance between strength and flexibility, joint stiffness, decreased bone density, and abnormal movement mechanics during the year of maximal growth contributes to an increase in traumatic injuries. Additionally if muscles, tendons, and apophyses adapt slowly, and activities are performed repetitively, those tissues are not immediately able to deal with the increased stress and overuse injuries may occur after PHV [4]. Body area injury location in boys is significantly different before and after PHV. Younger athletes are more likely to have bone fractures located in the upper limbs that are associated with traumatic injuries due to a transient decrease in coordination, balance, and complex motor skills [5]. On the other hand, increased stress occurs as the changes in the length, mass, and moment of inertia of the extremities take place with growth. These complex factors may be conducive to the development of overuse injuries, especially in lower limbs after PHV [6].

Due to the variation in timing of maturation, chronological age may not be an absolute indicator for injury risk and the assessment of maturation should be strongly encouraged.

Institutional Review Board Statement: The study was conducted according to the guidelines of the Declaration of Helsinki, and approved by the Ethics Committee of the Faculty of Human Kinetics, University of Lisbon (50/2015).

Informed Consent Statement: Informed consent was obtained from all subjects involved in the study.

Data Availability Statement: The data presented in this study are available on request from the corresponding author.

Acknowledgments: We would like to express our gratitude to Carlos Barrigas, Ana Silva, and João Albuquerque. Lara Costa e Silva, Ana Silva, and João Albuquerque were supported by a scholarship from FCT.

Conflicts of Interest: The authors declare no conflict of interest.

\section{References}

1. Silva, L.C.e.; Fragoso, I.; Teles, J. Injury Profile in Portuguese Children and Adolescents According to Their Level of Sports Participation. J. Sport Med. Phys. Fit. 2018, 58, 271-279.

2. Silva, L.C.e.; Fragoso, M.I.; Teles, J. Physical Activity-Related Injury Profile in Children and Adolescents According to Their Age, Maturation, and Level of Sports Participation. Sports Health 2017, 9, 118-125. [CrossRef]

3. Maffulli, N.; Caine, D. The Epidemiology of Children's Team Sports Injuries. Med. Sport Sci. 2005, 49, 1-8. [PubMed]

4. Van der Sluis, A.; Elferink-Gemser, M.T.; Coelho-e-Silva, M.J.M.; Nijboer, J.A.J.; Brink, M.S.M.; Visscher, C. Sport Injuries Aligned to Peak Height Velocity in Talented Pubertal Soccer Players. Int. J. Sports Med. 2014, 35, 351-355. [CrossRef] [PubMed]

5. Swenson, D.M.; Henke, N.M.; Collins, C.L.; Fields, S.K.; Comstock, R.D. Epidemiology of United States High School SportsRelated Fractures, 2008-09 to 2010-11. Am. J. Sports Med. 2012, 40, 2078-2084. [CrossRef] [PubMed]

6. DiFiori, J. Overuse injuries in children and adolescents. Curr. Sport Med. Rep. 2010, 9, 372-378. [CrossRef] [PubMed] 